\title{
Risk Analysis for Chemotherapy-induced Nausea and Vomiting (CINV) in Patients Receiving FEC100 Treatment
}

\author{
MITSUHIRO HAYASHI ${ }^{1}$, KYOKO NAKAZAWA ${ }^{2}$, YOSHIE HASEGAWA ${ }^{3}$, JUN HORIGUCHI ${ }^{4}$, DAISHU MIURA ${ }^{5}$, \\ TAKASHI ISHIKAWA ${ }^{6}$, SHINTARO TAKAO ${ }^{7}$, SEUNG JIM KIM ${ }^{8}$, KAZUHIKO YAMAGAMI ${ }^{9}$, \\ MASARU MIYASHITA ${ }^{10}$, MUNEHARU KONISHI ${ }^{11}$, YASUSHI SHIGEOKA ${ }^{12}$, MASATO SUZUKI ${ }^{13}$, \\ TETSUYA TAGUCHI ${ }^{14}$, TOMOYUKI KUBOTA ${ }^{15}$, HIROKAZU TANINO ${ }^{16}$, KIMITO YAMADA $^{17}$, \\ KAZUTAKA NARUI $^{18}$, KONOMI KIMURA ${ }^{2}$, KOHEI AKAZAWA ${ }^{2}$, NORIO KOHNO ${ }^{19}$ and JONIE STUDY GROUP \\ ${ }^{1}$ Breast Center, Dokkyo Medical University, Tochigi, Japan; \\ ${ }^{2}$ Department of Medical Informatics, Niigata University, Niigata, Japan; \\ ${ }^{3}$ Department of Breast Surgery, Hirosaki Municipal Hospital, Hirosaki, Japan; \\ ${ }^{4}$ Department of Breast Surgery, International University of Health and Welfare, Chiba, Japan; \\ ${ }^{5}$ Akasaka Miura Clinic, Tokyo, Japan; \\ ${ }^{6}$ Department of Breast Oncology, Tokyo Medical University, Tokyo, Japan; \\ ${ }^{7}$ Department of Breast Surgery, Hyogo Cancer Center, Hyogo, Japan; \\ ${ }^{8}$ Department of Breast and Endocrine Surgery, Osaka University, Osaka, Japan; \\ ${ }^{9}$ Department of Breast Oncology, Shinko Hospital, Hyogo, Japan; \\ ${ }^{10}$ Department of Surgery, Kohnan Hospital, Hyogo, Japan; \\ ${ }^{11}$ Department of Surgery, Hyogo Prefectural Nishinomiya Hospital, Hyogo, Japan; \\ ${ }^{12}$ Department of Medical Oncology, Yodogawa Christian Hospital, Osaka, Japan; \\ ${ }^{13}$ Department of Surgery, National Hospital Organization Chiba Medical Center, Chiba, Japan; \\ ${ }^{14}$ Department of Endocrine and Breast Surgery, Kyoto Prefectural University of Medicine, Kyoto, Japan; \\ ${ }^{15}$ Department of Surgery, Kamiiida Daiichi General Hospital, Aichi, Japan; \\ ${ }^{16}$ Department of Surgery, Kobe University, Hyogo, Japan; \\ ${ }^{17}$ Department of Breast Oncology, Hachioji Medical Center, Tokyo Medical University, Tokyo, Japan \\ ${ }^{18}$ Department of Breast and Endocrine Surgery, Yokohama City University Medical Center, Kanagawa, Japan; \\ ${ }^{19}$ Department of Breast Surgery, Kobe Kaisei Hospital, Hyogo, Japan
}

\begin{abstract}
Background/Aim: Risk factors for chemotherapyinduced nausea and vomiting (CINV) with anthracyclinecontaining regimen for breast cancer patients remain unknown. The risk factors for CINV with FEC100 were investigated. Patients and Methods: Data on CINV events and patient backgrounds of 180 patients were collected from the first cycle of FEC100 treatment. In this regimen, patients were administered various antiemetics (ADS). The combinations of $A D$ s were classified into four categories, while body mass index (BMI) was stratified into three categories. Risk factors
\end{abstract}

Correspondence to: Mitsuhiro Hayashi, Dokkyo Medical University, 880 Kitakobayashi, Mibu, Tochigi, 3210293, Japan. Tel: +81 282861111, Fax: +81 282872500, e-mail: hayashim@ dokkyomed.ac.jp

Key Words: CINV, anthracycline, breast cancer, antiemetic agents, low BMI, neurokinin-1 receptor antagonist. were selected based on patient characteristics and combination of ADs. Risks for CINV were analyzed by univariate and multivariate analyses. Results: In the univariate analysis of nausea, BMI was a significant factor, while BMI and combination of ADs were significant in vomiting. In the multivariate analysis concerning nausea, BMI was a significant factor. In the analysis concerning vomiting, the combination of ADs and BMI were significant. Conclusion: BMI was the most important risk factor for nausea and vomiting, while the combination of $A D$ s was for vomiting.

In 1978, Rosal et al., first showed that postoperative chemotherapy with cyclophosphamide plus methotrexate plus 5-fluorouracil (CMF) reduced recurrence and survival in patients with breast cancer compared to surgery alone (1). Since the 1980s, anthracycline-containing regimens have taken the place of CMF as standard chemotherapy (2-8). As its anticancer effect is still high, it is one of the standard treatment options for breast cancer patients. However, 


\section{Trial profile}

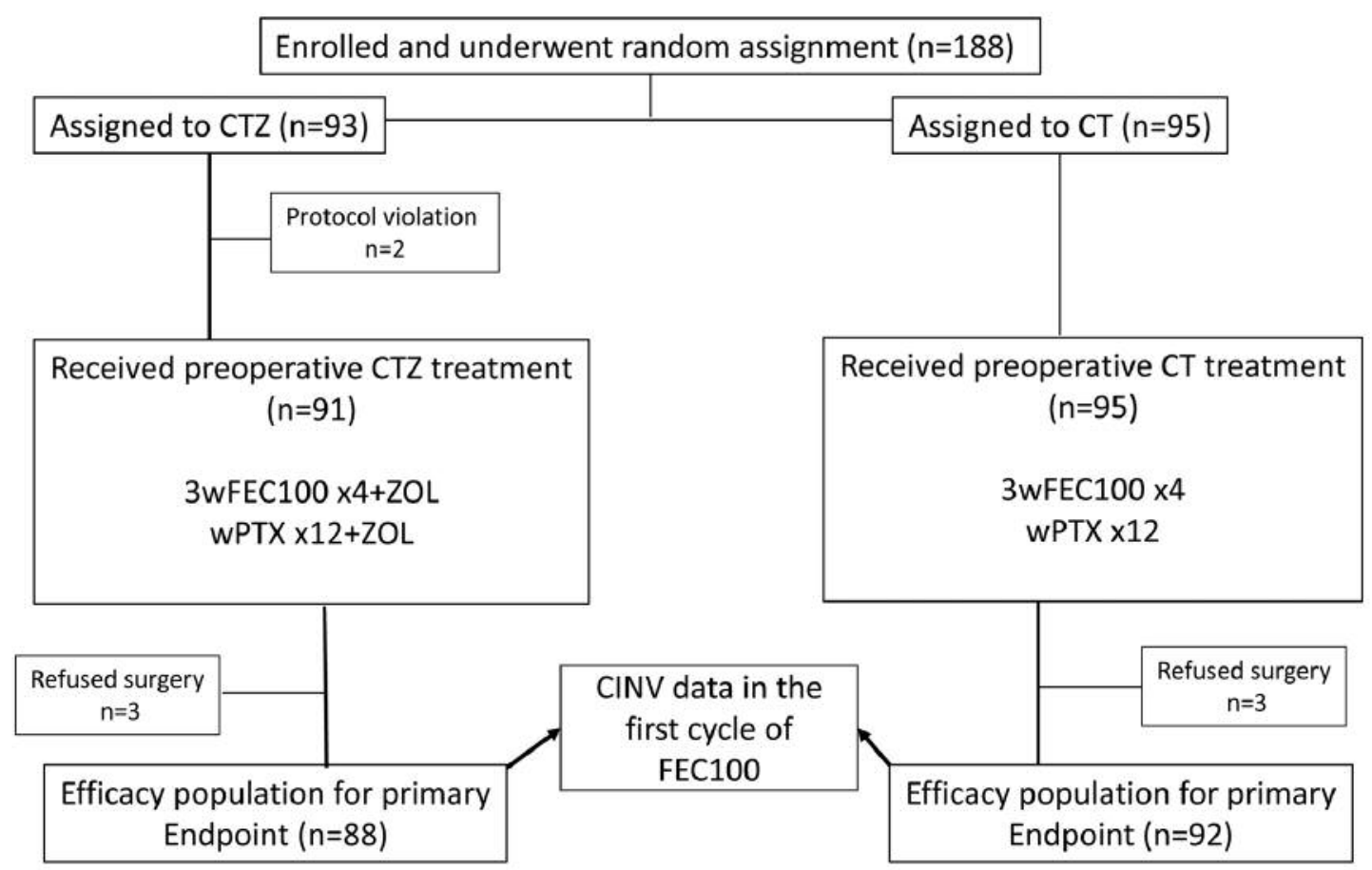

Figure 1. Diagram showing the study design of the JONIE study. A total of 188 patients were enrolled in this study. Two protocol violations occurred in the CTZ group. Three patients refused surgery in each of the groups. Finally, CINV data from the first cycle of FEC100 treatment were collected and used in this study. CTZ: Chemotherapy plus Zoledronic acid; CT: chemotherapy; FEC100: 5-FU plus Epirubicin 100 mg/m ${ }^{2}$ plus Cyclophosphamide treatment; wPTX: weekly paclitaxel treatment; CINV: chemotherapy-induced nausea and vomiting.

control of chemotherapy-induced nausea and vomiting (CINV) for those who receive anthracycline-based treatment is a most important supportive measure even now.

We conducted a clinical trial to investigate whether or not addition of bisphosphonates led to a superior clinical outcome in the neoadjuvant setting (JONIE study) (9). In this study, the FEC100 regimen was used in the initial treatment. The primary endpoint of this study was the pathological complete response (pCR) rate following neoadjuvant chemotherapy. However, during chemotherapy, data concerning nausea and vomiting grade were also collected.

Although we defined the dose of anticancer drugs, the timing and the dose reduction protocol, as well as the selection of antiemetic agents were scheduled depending on each physician's personal preference. For these reasons, we speculated that the combination of antiemetic agents may be one significant factor affecting the CINV grade. To test this hypothesis, we investigated the relationship between CINV and patient characteristics and the combination of antiemetic drugs. The purpose of this study was to elucidate the risk factors for CINV in patients undergoing FEC100 treatment.

\section{Patients and Methods}

Study design and patients. A randomized controlled trial was conducted to evaluate the efficacy of zoledronic acid (ZOL) in the neoadjuvant setting for breast cancer patients (JONIE study) (9). From March 2010 to June 2012, 188 patients were recruited to the JONIE study. An outline of the study design is shown in Figure 1. The eligibility criteria have been described in our previous publications $(9,10)$. The raw data from 180 patients in the JONIE study were available for analysis in this study.

Treatment. In the JONIE study, four cycles of FEC100 (5-fluorouracil $500 \mathrm{mg} / \mathrm{m}^{2}$, epirubicin $100 \mathrm{mg} / \mathrm{m}^{2}$, cyclophosphamide $100 \mathrm{mg} / \mathrm{m}^{2}$ ) were administered by intravenous infusion every 3 weeks followed by 12 cycles of paclitaxel at $80 \mathrm{mg} / \mathrm{m}^{2}$ by intravenous infusion weekly in the groups treated with and without ZOL. Study participants were stratified into two groups: i) a chemotherapy plus zoledronic acid (CTZ) group and ii) a chemotherapy alone (CT) group.

In the CTZ group, ZOL (4 mg) was administered by intravenous infusion on day 1 of every FEC treatment cycle. Following the completion of the FEC therapy, ZOL was also administered three times every 4 weeks during weekly paclitaxel treatment (Figure 1).

Variables. Table I shows the variables used in this study: i) age at randomization, ii) menopausal status, iii) tumor-node-metastasis 
Hayashi et al: Risk of Chemotherapy-Induced Nausea and Vomiting in FEC100 Treatment

(TNM) stage, iv) lymph node metastasis, v) type of study treatment, vi) combination of antiemetic drugs and vii) BMI.

Age at randomization was divided into four categories: i) 39 years old or less, ii) 40 to 49 years inclusive, iii) 50 to 59 years inclusive and iv) 60 years old or more. TNM staging was also divided into four categories: i) IIA, ii) IIB, iii) IIIA and iv) IIIB.

Study treatment was divided into: i) the CTZ group and ii) the $\mathrm{CT}$ group. Various types of antiemetic agents were administered in the first cycle of the FEC100 regimen in this study. The antiemetic drugs were combined into four categories: i) Dexamethasone (DEX) $+5-\mathrm{HT}_{3}$ receptor antagonist $\left(5-\mathrm{HT}_{3}\right)+$ neurokinin-1 receptor antagonist $\left(\mathrm{NK}_{1}\right)$, ii) $\mathrm{DEX}+5-\mathrm{HT}_{3}$, iii) $\mathrm{DEX}+5-\mathrm{HT}_{3}+$ dopamine receptor antagonist (DRA) and iv) $\mathrm{DEX}+5-\mathrm{HT}_{3}+\mathrm{NK}_{1}+\mathrm{DRA}$.

BMI was stratified into three categories: i) less than 18.5 , ii) 18.5 or more but less than 25 , and iii) 25 or more.

Outcomes. The outcomes of this study were defined as two event occurrences: i) nausea and ii) vomiting, and were evaluated separately. Each adverse event (AE) was graded according to CTCAE version 3.0(11). No AEs was defined as grade 0 and grades 1 to 3 were positive AEs. All AEs were estimated based on the worst symptoms experienced during the first cycle of FEC 100 treatment. We did not divide these AEs into acute (occurring within 24 hours) and delayed (24 hours or later) phase emesis.

Ethics. The study was performed in accordance with the International Conference on Harmonization guidelines concerning Good Clinical Practice (12) and the Declaration of Helsinki (13). Furthermore, it was approved by the institutional review board of every participating institution and all patients showed their willingness to take part in the JONIE study by providing a written informed consent. This study was registered at the University Hospital Medical Information Network as UMIN000003261 (www.umin.ac.jp/english/).

Statistical analysis. Univariate analysis was performed to clarify the relationship between CINV and candidate factors. Pearson's Chisquare or Fisher's exact tests were performed to compare the proportions of several groups for discrete variables. The MannWhitney $U$-test was used to test the equality of distribution of the two groups for continuous and ordered variables. Univariate logistic regression analysis was performed to calculate the odds ratio (OR) for each factor. Multiple logistic regression analysis using the forward stepwise method was carried out to elucidate the significant risk factors for nausea and vomiting.

$p$-Values of less than 0.05 were considered to indicate statistical significance. All estimation and testing was performed using SPSS software, version 17.0 (SPSS Inc., Chicago, IL, USA).

\section{Results}

Median age (25th percentile, 75 th percentile) of 180 patients were $49(43,58)$, and eighty-eight patients underwent CTZ treatment. The numbers of patients suffering from nausea and vomiting were 84 and 27 , respectively.

Table II shows the results of cross tabulation between clinical characteristics and nausea. Analysis by Chi-squared test and Mann-Whitney $U$-test indicated that BMI significantly associated with the occurrence of nausea; that
Table I. Patient characteristics.

\begin{tabular}{|c|c|c|}
\hline Variables & $\begin{array}{c}\text { Number of } \\
\text { patients }\end{array}$ & $\begin{array}{c}\text { Percentage of } \\
\text { patients }\end{array}$ \\
\hline Overall & 180 & 100 \\
\hline \multicolumn{3}{|l|}{ Age (years) } \\
\hline$\leq 39$ & 26 & 14.4 \\
\hline $40-49$ & 65 & 36.1 \\
\hline $50-59$ & 53 & 29.4 \\
\hline$\geq 60$ & 36 & 20.0 \\
\hline \multicolumn{3}{|l|}{ Menopausal status } \\
\hline Premenopausal & 104 & 57.8 \\
\hline Postmenopausal & 76 & 42.2 \\
\hline \multicolumn{3}{|l|}{ TNM stage } \\
\hline IIA & 55 & 30.6 \\
\hline IIB & 83 & 46.1 \\
\hline IIIA & 30 & 16.7 \\
\hline IIIB & 12 & 6.7 \\
\hline \multicolumn{3}{|l|}{ Lymph node metastasis } \\
\hline Negative & 64 & 35.6 \\
\hline Positive & 116 & 64.4 \\
\hline \multicolumn{3}{|l|}{ Type of study treatment } \\
\hline CTZ & 88 & 48.9 \\
\hline $\mathrm{CT}$ & 92 & 51.1 \\
\hline \multicolumn{3}{|l|}{ Combination of antiemetics } \\
\hline $\mathrm{DEX}+5-\mathrm{HT}_{3}+\mathrm{NK}_{1}$ & 98 & 54.4 \\
\hline $\mathrm{DEX}+5-\mathrm{HT}_{3}$ & 42 & 23.3 \\
\hline $\mathrm{DEX}+5-\mathrm{HT}_{3}+\mathrm{DRA}$ & 25 & 13.9 \\
\hline $\mathrm{DEX}+5-\mathrm{HT}_{3}+\mathrm{NK}_{1}+\mathrm{DRA}$ & 15 & 8.3 \\
\hline \multicolumn{3}{|l|}{ BMI $\left(\mathrm{kg} / \mathrm{m}^{2}\right)$} \\
\hline$<18.5$ & 21 & 11.7 \\
\hline $18.5 \leq \mathrm{BMI}<25$ & 126 & 70.0 \\
\hline $25 \leq \mathrm{BMI}$ & 33 & 18.3 \\
\hline
\end{tabular}

CTZ: Chemotherapy plus Zoledronic acid; CT: Chemotherapy alone; DEX: Dexamethasone; 5- $\mathrm{HT}_{3}: 5-\mathrm{HT}_{3}$ receptor antagonist, $\mathrm{NK}_{1}$ : neurokinin-1 receptor antagonist; DRA: dopamine receptor antagonist; BMI: body mass index.

is, patients with a BMI of less than 18.5 were more likely to experience nausea.

Similarly, the results of univariate analysis for the outcome of vomiting are shown in Table III. The combination of antiemetics and BMI were variables significantly associated with the occurrence of vomiting. In particular, the occurrence rates in the $\mathrm{DEX}+5-\mathrm{HT}_{3}$ and $\mathrm{DEX}+5-\mathrm{HT}_{3}+\mathrm{DRA}$ groups were $23.8 \%$ and $32.0 \%$, respectively, which were considerably higher compared to the rates of $7.1 \%$ and $13.3 \%$ in the $\mathrm{DEX}+5-\mathrm{HT}_{3}+\mathrm{NK}_{1}$ and $\mathrm{DEX}+5-\mathrm{HT}_{3}+\mathrm{NK}_{1}+\mathrm{DRA}$ groups, respectively. Moreover, the patient group with the lower BMI had a higher occurrence rate of vomiting.

In univariate logistic regression analysis of nausea, the chi-square test and Fisher's exact test showed that menopausal status, lymph node metastasis and type of study treatment were not statistically-significant variables. The Mann-Whitney $U$-test revealed that age at randomization, TNM stage and combination of antiemetics were not 
Table II. Univariate analysis of nausea.

\begin{tabular}{|c|c|c|c|c|}
\hline Variables & $\begin{array}{c}\text { Number of patients } \\
n=180(\%)\end{array}$ & $\begin{array}{c}\text { Patients without nausea } \\
\mathrm{n}=96(\%)\end{array}$ & $\begin{array}{c}\text { Patients with nausea } \\
n=84(\%)\end{array}$ & $p$-Value \\
\hline Age (years) & & & & 0.83 \\
\hline$\leq 39$ & $26(100)$ & $12(46.2)$ & $14(53.8)$ & \\
\hline $40-49$ & $65(100)$ & $37(56.9)$ & $28(43.1)$ & \\
\hline $50-59$ & $53(100)$ & $28(52.3)$ & $25(47.7)$ & \\
\hline$\geq 60$ & $36(100)$ & $19(52.8)$ & $17(47.2)$ & \\
\hline Menopausal status & & & & 0.171 \\
\hline Premenopausal & $104(100)$ & $60(57.7)$ & $44(42.3)$ & \\
\hline Postmenopausal & $76(100)$ & $36(47.4)$ & $40(52.6)$ & \\
\hline TNM stage & & & & 0.903 \\
\hline IIA & $55(100)$ & $31(56.4)$ & $24(43.6)$ & \\
\hline IIB & $83(100)$ & $42(50.6)$ & $41(49.4)$ & \\
\hline IIIA & $30(100)$ & $16(53.3)$ & $14(46.7)$ & \\
\hline IIIB & $12(100)$ & $7(58.3)$ & $5(41.7)$ & \\
\hline Lymph node metastasis & & & & 0.371 \\
\hline Negative & $64(100)$ & $37(57.8)$ & $27(42.2)$ & \\
\hline Positive & $116(100)$ & $59(50.9)$ & $57(49.1)$ & \\
\hline Type of treatment & & & & 0.78 \\
\hline CTZ & $88(100)$ & $46(52.3)$ & $42(47.7)$ & \\
\hline $\mathrm{CT}$ & $92(100)$ & $50(54.3)$ & $42(45.7)$ & \\
\hline Combination of antiemetics & & & & 0.522 \\
\hline $\mathrm{DEX}+5-\mathrm{HT} 3+\mathrm{NK} 1$ & $98(100)$ & $56(57.1)$ & $42(42.9)$ & \\
\hline $\mathrm{DEX}+5-\mathrm{HT} 3$ & $42(100)$ & $20(47.6)$ & $22(52.4)$ & \\
\hline $\mathrm{DEX}+5-\mathrm{HT} 3+\mathrm{DRA}$ & $25(100)$ & $11(44.0)$ & $14(56.0)$ & \\
\hline $\mathrm{DEX}+5-\mathrm{HT} 3+\mathrm{NK} 1+\mathrm{DRA}$ & $15(100)$ & $9(60.0)$ & $6(40.0)$ & \\
\hline BMI $\left(\mathrm{kg} / \mathrm{m}^{2}\right)$ & & & & $0.002 *$ \\
\hline$<18.5$ & $21(100)$ & $3(14.3)$ & $18(85.7)$ & \\
\hline $18.5 \leq \mathrm{BMI}<25$ & $126(100)$ & $71(56.3)$ & $55(43.7)$ & \\
\hline $25 \leq$ & $33(100)$ & $22(66.7)$ & $11(33.3)$ & \\
\hline
\end{tabular}

CTZ: Chemotherapy plus Zoledronic acid; CT: Chemotherapy alone; DEX: Dexamethasone; $5-\mathrm{HT}_{3}: 5-\mathrm{HT}_{3}$ receptor antagonist; $\mathrm{NK}_{1}$ : neurokinin-1 receptor antagonist; DRA: dopamine receptor antagonist; BMI: body mass index.

significantly related to the incidence of nausea, while BMI was the only significant variable $(p=0.002)$ (Table II).

Compared to the control group (BMI of 18.5 or more but less than 25), the group with BMI less than 18.5 showed a significantly higher risk of nausea $(p=0.002)$ and the OR of BMI less than 18.5 was 7.745 [95\% confidence interval $(95 \% \mathrm{CI})=2.171-27.634]$ (Figure 2).

On the other hand, in univariate logistic regression analysis of vomiting, chi-square test and Fisher's exact test showed that menopausal status, lymph node metastasis and type of study treatment were not statistically-significant variables. The Mann-Whitney $U$-test showed that age at randomization and TNM stage were not significant, whereas the combination of antiemetics and BMI were significant variables, with $p$ Values of 0.009 and 0.008 , respectively (Table III). Furthermore, as the combination of antiemetics in the $\mathrm{DEX}+5-\mathrm{HT}_{3}+\mathrm{NK}_{1}$ group was the control combination, the ORs of the DEX+5- $\mathrm{HT}_{3}$ group and the DEX+5$\mathrm{HT}_{3}+\mathrm{NK}_{1}+\mathrm{DRA}$ group were 4.502 and $6.118(95 \% \mathrm{CI}=1.427-$ 11.569 and 1.959-19.108), respectively (Figure 3). In addition, compared to the control group (BMI of 18.5 or more to 25$)$, BMI of less than 18.5 showed a significantly higher risk of vomiting ( $p=0.008)$, and the OR of BMI of less than 18.5 was $3.946(95 \% \mathrm{CI}=1.425-10.923)$ (Figure 3$)$.

Multiple logistic regression analysis for nausea indicated that the BMI category of less than 18.5 had a $p$-Value of 0.002 , while the OR was 7.745 (95\%CI-2.171-27.634) compared to the control BMI as baseline. This result was the same as the result of the univariate analysis of nausea. Thus a BMI of less than 18.5 was associated with a 7.745-times higher incident risk of nausea. However, a BMI of 25 or more showed no significant association $(p=0.286)$ (Figure 2).

On the other hand, in multiple logistic regression analysis for vomiting, BMI and the combination of antiemetic drugs were significant variables, with $p$-Values of 0.025 and 0.023 , respectively. The OR of BMI less than 18.5 was 3.481 (95\%CI $=1.183-10.241, p=0.023)$ compared to the control BMI group. However, a BMI of 25 or more was not significant, indicating that a BMI of less than 18.5 was associated with a 3.481-times higher incident risk of vomiting. 
Table III. Univariate analysis of vomiting.

\begin{tabular}{|c|c|c|c|c|}
\hline Variables & $\begin{array}{c}\text { Number of patients } \\
\mathrm{n}=180(\%)\end{array}$ & $\begin{array}{c}\text { Patients without vomiting } \\
\mathrm{n}=153(\%)\end{array}$ & $\begin{array}{c}\text { Patients with vomiting } \\
\mathrm{n}=27(\%)\end{array}$ & $p$-Value* \\
\hline Age (years) & & & & 0.887 \\
\hline$\leq 39$ & $26(100)$ & $23(88.5)$ & $3(11.5)$ & \\
\hline $40-49$ & $65(100)$ & $54(83.1)$ & $11(16.9)$ & \\
\hline $50-59$ & $53(100)$ & $46(86.8)$ & $7(13.2)$ & \\
\hline$\geq 60$ & $36(100)$ & $30(83.3)$ & $6(16.7)$ & \\
\hline Menopausal status & & & & 0.500 \\
\hline Premenopausal & $104(100)$ & $90(86.5)$ & $14(13.5)$ & \\
\hline Postmenopausal & $76(100)$ & $63(82.9)$ & $13(17.1)$ & \\
\hline TNM stage & & & & 0.657 \\
\hline IIA & $55(100)$ & $46(83.6)$ & $9(16.4)$ & \\
\hline IIB & $83(100)$ & $73(88.0)$ & $10(12.0)$ & \\
\hline IIIA & $30(100)$ & $25(83.3)$ & $5(16.7)$ & \\
\hline IIIB & $12(100)$ & $9(75.0)$ & $3(25.0)$ & \\
\hline Lymph node metastasis & & & & 0.794 \\
\hline Negative & $64(100)$ & $55(85.9)$ & $9(14.1)$ & \\
\hline Positive & $116(100)$ & $98(84.5)$ & $18(15.5)$ & \\
\hline Type of treatment & & & & 0.617 \\
\hline CTZ & $88(100)$ & $76(86.4)$ & $12(13.6)$ & \\
\hline $\mathrm{CT}$ & $92(100)$ & $77(83.7)$ & $15(16.3)$ & \\
\hline Combination of antiemetics & & & & $0.009 *$ \\
\hline $\mathrm{DEX}+5-\mathrm{HT} 3+\mathrm{NK}_{1}$ & $98(100)$ & $91(92.9)$ & $7(7.1)$ & \\
\hline $\mathrm{DEX}+5-\mathrm{HT} 3$ & $42(100)$ & $32(76.2)$ & $10(23.8)$ & \\
\hline DEX+5-HT3+DRA & $25(100)$ & $17(68.0)$ & $8(32.0)$ & \\
\hline $\mathrm{DEX}+5-\mathrm{HT} 3+\mathrm{NK}_{1}+\mathrm{DRA}$ & $15(100)$ & $13(86.7)$ & $2(13.3)$ & \\
\hline $\operatorname{BMI}\left(\mathrm{kg} / \mathrm{m}^{2}\right)$ & & & & $0.008 *$ \\
\hline$<18.5$ & $21(100)$ & $13(61.9)$ & $8(38.1)$ & \\
\hline $18.5 \leq \mathrm{BMI}<25$ & $126(100)$ & $109(86.5)$ & $17(13.5)$ & \\
\hline $25 \leq$ & $33(100)$ & $31(93.9)$ & $2(6.1)$ & \\
\hline
\end{tabular}

CTZ: Chemotherapy plus Zoledronic acid; CT: chemotherapy alone; DEX: dexamethasone; 5-HT3: 5-HT3 receptor antagonist; NK $_{1}$ : neurokinin-1 receptor antagonist; DRA: dopamine receptor antagonist; BMI: body mass index.

Meanwhile, the $p$-Value of the combination of antiemetics was 0.023 . ORs in the DEX+5- $\mathrm{HT}_{3}+\mathrm{DRA}$ group and the $\mathrm{DEX}+5-\mathrm{HT}_{3}$ group were $5.005(95 \% \mathrm{CI}=1.543-16.239$, $p=0.007)$ and $4.178 \quad(95 \% \mathrm{CI}=1.428-12.222, \quad p=0.009)$ compared to the $\mathrm{DEX}+5-\mathrm{HT}_{3}+\mathrm{NK}_{1}$ group as baseline. This indicates that treatment with $\mathrm{DEX}+5-\mathrm{HT}_{3}+\mathrm{DRA}$ or $\mathrm{DEX}+5 \mathrm{HT}_{3}$ was associated with a 5.005 and 4.148-times higher incident risk of vomiting, respectively, compared to $\mathrm{DEX}+5-\mathrm{HT}_{3}+\mathrm{NK}_{1}$ treatment (Figure 4).

With regards to vomiting, we also conducted another analysis. Because the categories of antiemetic drug combinations were complicated and hard to understand, we re-stratified the treatments into two categories: i) an $\mathrm{NK}_{1^{-}}$ containing group and ii) a no- $\mathrm{NK}_{1}$ group. After recategorizing, this factor was included as a risk factor. In this additional study, BMI and antiemetic combination were significant variables for vomiting in the multivariate analysis. The $p$-Values of antiemetic combination and BMI were 0.002 and 0.025 , respectively. The $\mathrm{OR}$ of the no- $\mathrm{NK}_{1^{-}}$ containing group was 3.906 (95\% CI=1.621-9.434, $p=0.002)$.
This result revealed that antiemetic drug combinations without $\mathrm{NK}_{1}$ resulted in a 3.906-times higher risk of vomiting compared to $\mathrm{NK}_{1}$-containing combinations. The OR of BMI less than 18.5 was 3.639 (95\% CI=1.251-10.586, $p=0.018$ ) compared to the control BMI group; however, BMI of 25 or more was not significant (Figure 5).

\section{Discussion}

This study involved post-hoc analysis of the data from the JONIE study. Endpoints of this study were as follows. First, it aimed to investigate significant risk factors for nausea and vomiting by univariate analysis among the first cycle of FEC100 treatment. Second, significant factors identified by univariate analysis were examined by multivariate analysis.

With regard to nausea, BMI was the most important risk factor. Despite antiemetic drug support, low body-weight patients were more likely to experience nausea compared to standard or overweight patients. On the other hand, with regard to vomiting, both BMI and the combination of 


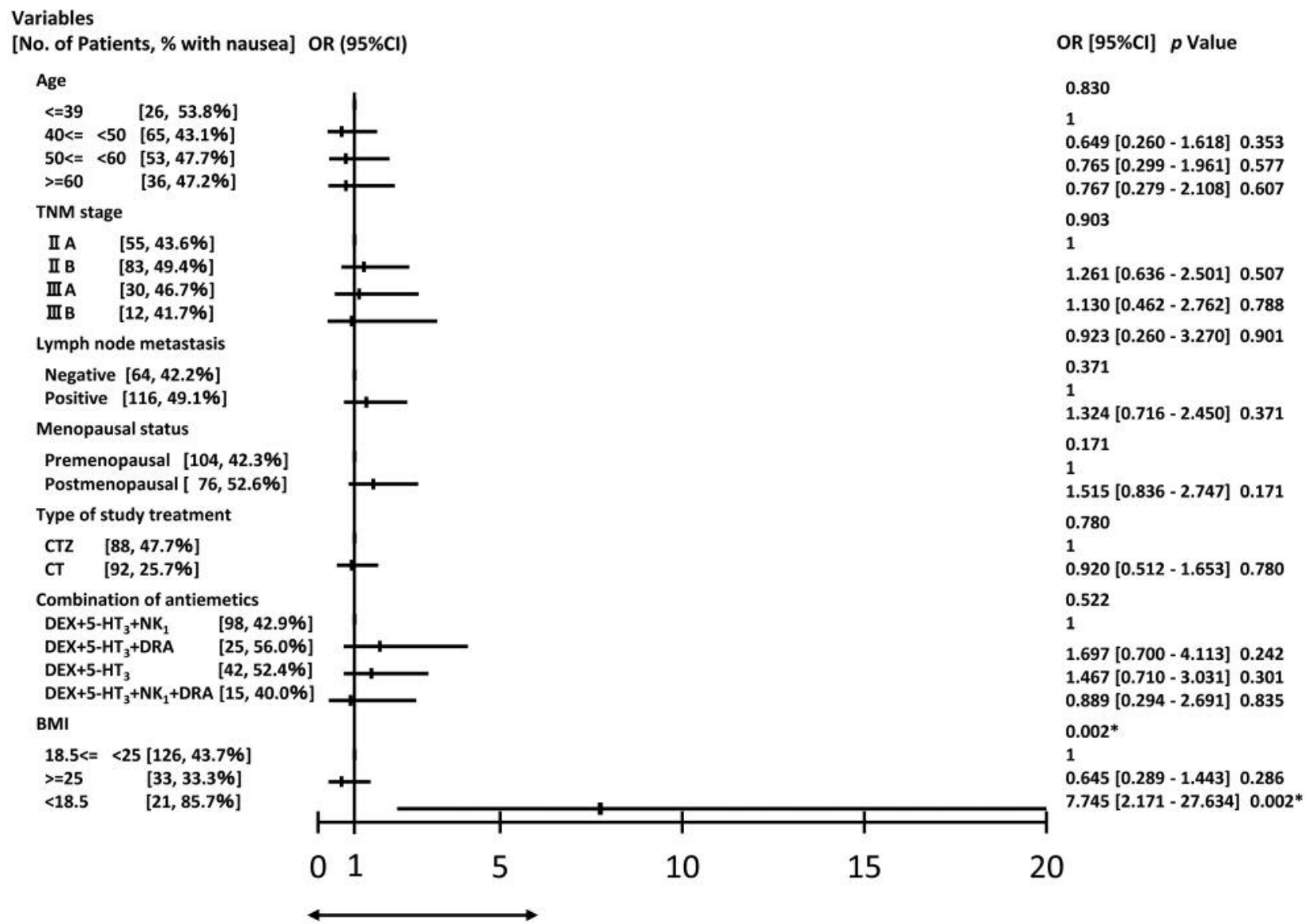

Figure 2. The results of univariate analysis of nausea. BMI was a significant variable, with a p-Value of 0.002. Asterisk points to statistical significance. BMI: body mass index.

antiemetic drugs were significant risk factors. To simplify the effect of antiemetic drugs, we opted to select according to whether $\mathrm{NK}_{1}$ was added or not as a prognostic factor, and found that low BMI and no $\mathrm{NK}_{1}$ were risk factors for vomiting. $\mathrm{NK}_{1}$-containing antiemetic regimens were associated with a 3.906-times lower vomiting risk compared to regimens without $\mathrm{NK}_{1}$.

Risk factors for CINV have been investigated in many studies (14-17). Sekine et al., have investigated risk factors for CINV in 1,549 chemotherapy-naïve patients. They revealed that female gender, younger age ( $<55$ years old $)$, non-habitual alcohol consumption and non-smoking were associated with treatment failure in the acute phase. On the other hand, only female gender was associated with treatment failure in the delayed phase (14). Warr also reviewed prognostic factors for CINV. He associated risk of CINV with type of antiemetic drugs, anxiety, expectation, concomitant administration of opioids and concomitant administration of serotonin specific reuptake inhibitors
(SSRI) (15). However, in his review, low body weight and additional administration of $\mathrm{NK}_{1}$ were not mentioned as risk factors for CINV.

Hesketh et al., conducted a randomized controlled trial to estimate the effectiveness of aprepitant-containing antiemetic drug regimens in CINV. They compared a $\mathrm{DEX}+5-\mathrm{HT}_{3}+\mathrm{NK}_{1}$ group to a $\mathrm{DEX}+5-\mathrm{HT}_{3}$ group and assessed the relationship between other risk factors and CINV. They found that $\mathrm{NK}_{1}$-containing regimens, male gender, lower cisplatin dose, older age (65 years or more), and five or more alcoholic drinks per week were significantly associated with improved complete response (16). Lorusso et al., have recently emphasized that it is important to use $\mathrm{DEX}+\mathrm{NK}_{1}$ (netupitant) and $5-\mathrm{HT}_{3}$ (palonosetoron) in patients with anthracycline plus cyclophosphamide (AC)-based chemotherapy (17). Their result that $\mathrm{NK}_{1}$-containing regimens were a significant factor was consistent with our study. However, age was not a significant factor in our study. 


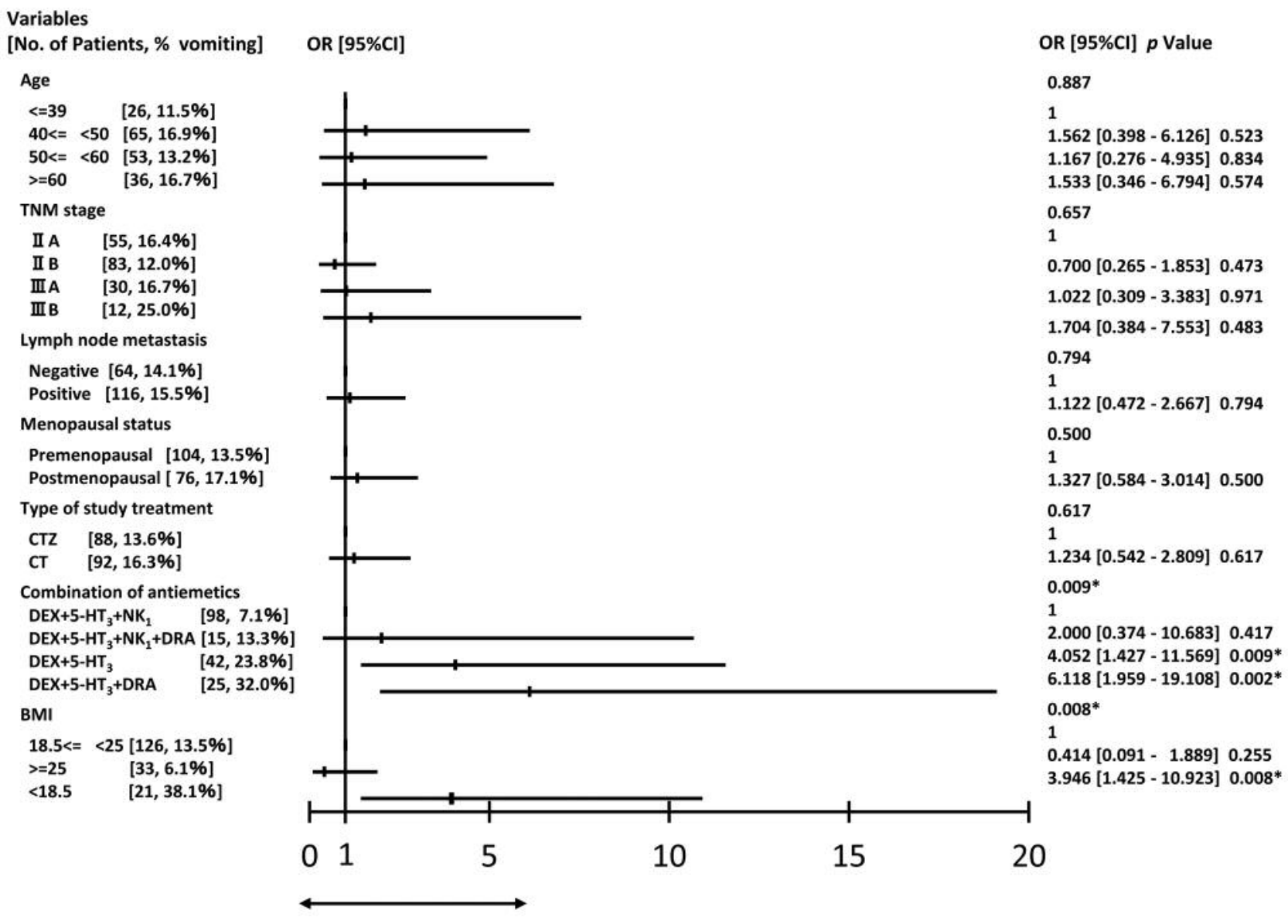

Figure 3. The results of univariate analysis of vomiting. BMI and combination of antiemetics were significant variables, with p-Values of 0.008 and 0.009 , respectively. Asterisk points to statistical significance.

There have only been a few studies into the relationship between body weight and CINV. Davidson et al., have investigated the relationship between malnutrition and CINV during chemotherapy in Australian patients. They concluded that $26 \%$ of patients were malnourished during chemotherapy. Furthermore, CINV had a significant relationship with intake limitation. Among participants, obese or overweight patients (BMI $\geq 25$ ) tended to experience body weight loss (18). This result contrasts with the findings of our study. This may be because they enrolled only a small number of low BMI patients in the study. Among the Australian population, only $2.1 \%$ of females aged 18 years or more was underweight $(\mathrm{BMI}<18.5)$ in 2014 (19). On the other hand, $11.7 \%$ of participants were categorized as underweight in our study. Our study is the first to report a relationship between low BMI and CINV incidence. However, it will be necessary to further investigate why thin women tend to have a high incidence of CINV.

Our study has some important limitations. First, the present study involved post-hoc research of the JONIE study.
This resulted in a non-randomized study of the antiemetic combinations. According to the American Society of Clinical Oncology (ASCO) antiemetic guidelines in $2011(20,21)$, $\mathrm{DEX}+5 \mathrm{HT}_{3}+\mathrm{NK}_{1}$ was recommended for AC-containing regimens. Moreover, the JONIE study recruited patients from 2010 to $2012(9,10)$. During the recruiting period, the ASCO antiemetic guidelines were updated from the 2006 first edition (22) to the 2011 update. Under these circumstances, various antiemetic combinations had to be provided in each institute. However, over half $(54.4 \%)$ of patients were administered 2011 guideline-adherent antiemetics. Second, we were unable to record CINV events in the early and delayed phases separately, because we did not consider collecting detailed CINV data before starting the JONIE study protocol.

In conclusion, BMI was a significant prognostic factor for nausea with FEC100 treatment, while both BMI and antiemetic combination were significant prognostic factors for vomiting. In other words, lower BMI was a significant risk factor for 


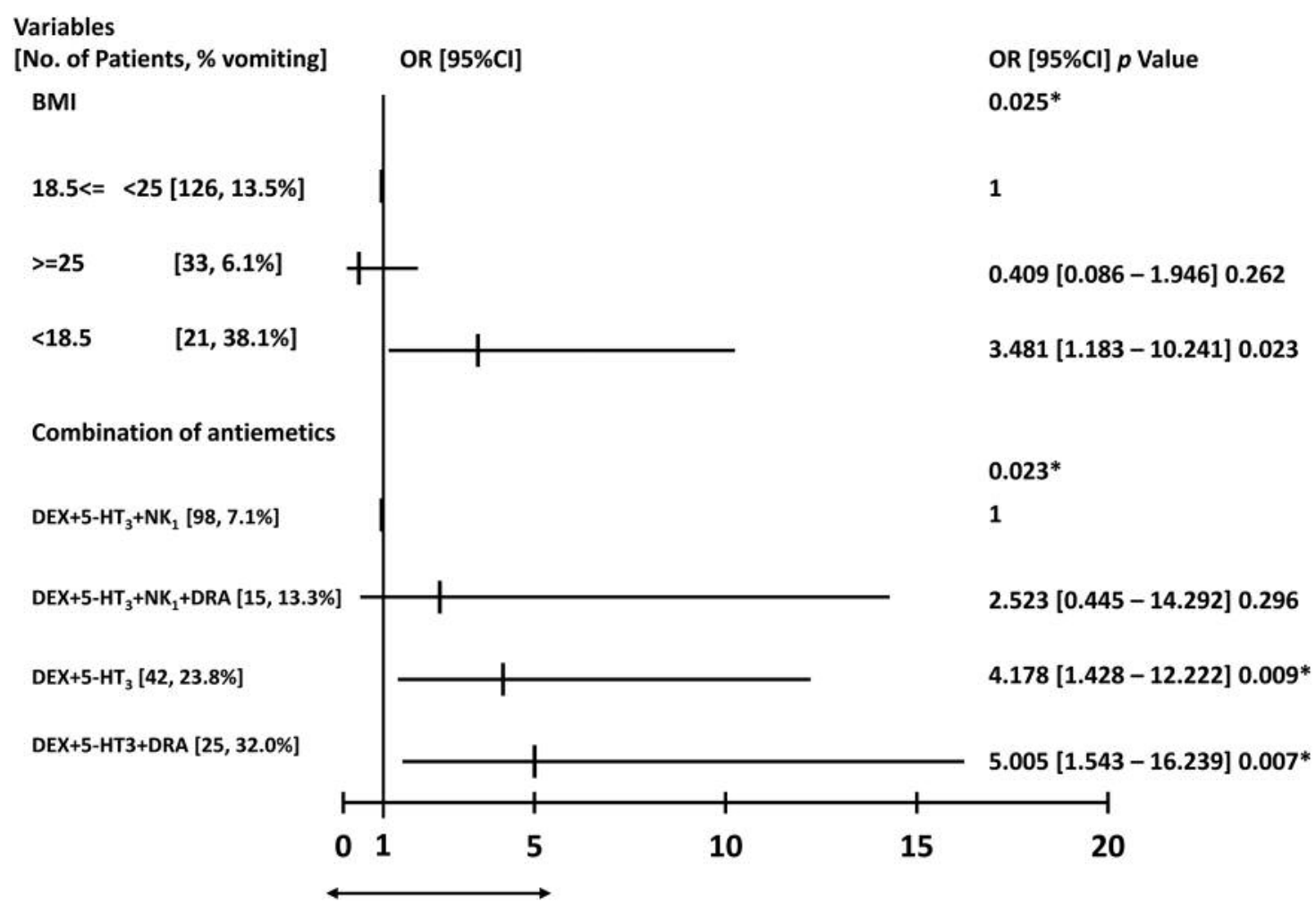

Figure 4. The results of multivariate regression analysis of vomiting. BMI and combination of antiemetics were significant variables, with p-Values of 0.025 and 0.023 , respectively. The OR for BMI less than 18.5 was 3.481 and p-Value was 0.023 . Meanwhile the OR for the DEX+5-HT $+D R A$ combination of antiemetics was 5.005 and for DEX+5-HT 3 was 0.009. Asterisk points to statistical significance. OR: Odds ratio; DEX: dexamethasone; 5-HT $T_{3}: 5-H T_{3}$ receptor antagonist; DRA: dopamine receptor antagonist.

both nausea and vomiting. $\mathrm{NK}_{1}$-containing antiemetic regimens were the best combination to prevent nausea. ASCO, National Comprehensive Cancer Network (NCCN) and Multinational Association of Supportive Care Cancer/European Society of Medical Oncology (MASCC/ESMO) antiemetic guidelines recommend $\mathrm{DTX}+5 \mathrm{HT}_{3}+\mathrm{NK}_{1}+$ olanzapine for AC-containing regimens to prevent CINV (23-27). Further investigation will be needed to ascertain the efficacy of the current guidelines in patients with low BMI.

\section{Conflicts of Interest}

MH received funding from Chugai, Daiichi Sankyo, Eisai, Pfizer, Taiho for contracted or investigator initiated research. This money was paid to Dokkyo Medical University. TI received funding from Chugai, Daiichi Sankyo, Eisai, Kyowa Kirin, Lilly, Pfizer, Sanofi, Shionogi, Taiho for contracted or investigator-initiated research. This money is paid to Tokyo Medical University. KY received funding from Eisai for contracted or investigator initiated research. This money was paid to Shinko Hospital. TT received funding from Chugai, Daiichi Sankyo, Eisai, Kyowa Kirin, Taiho for contracted or investigator initiated research or honoraria (lecture fee). This money is paid to Kyoto Prefectural University of Medicine. HT received funding from Ono, Sysmex, Taiho for contracted or investigator-initiated research. This money was paid to Kobe University. KY received funding from Chugai, Daiichi Sankyo, Eisai, Kyowa Kirin, Taiho for contracted or investigator-initiated research. This money was paid to Tokyo Medical University. NR received funding from Chugai, Daiichi Sankyo, Eisai, Taiho for contracted or investigator-initiated research. This money was paid to Yokohama City University. Other authors have no competing interests to declare.

\section{Authors's Contribution}

Study Conception bc by MH, KA, KN, KK,NK and study design by NK, KA, MH, YH, JH, DM, TI, ST, MM, MS, TK, HT. Acquisition of data was by MH, YH, JH, DM, TI, ST, SJK, KY, MM, MK, YS, MS, TT, TK, KY, KN, NK. MH, KA, and NK drafted and revised the manuscript. All authors have revised and approved the final version.

\section{Acknowledgements}

The Authors would like to thank all patients and their families for participation of the study. The Authors would also like to thank Mari Watanabe for supporting statistical analysis. This research did not receive any specific grant from funding agencies in public, commercial, or not-for-profit sectors. 


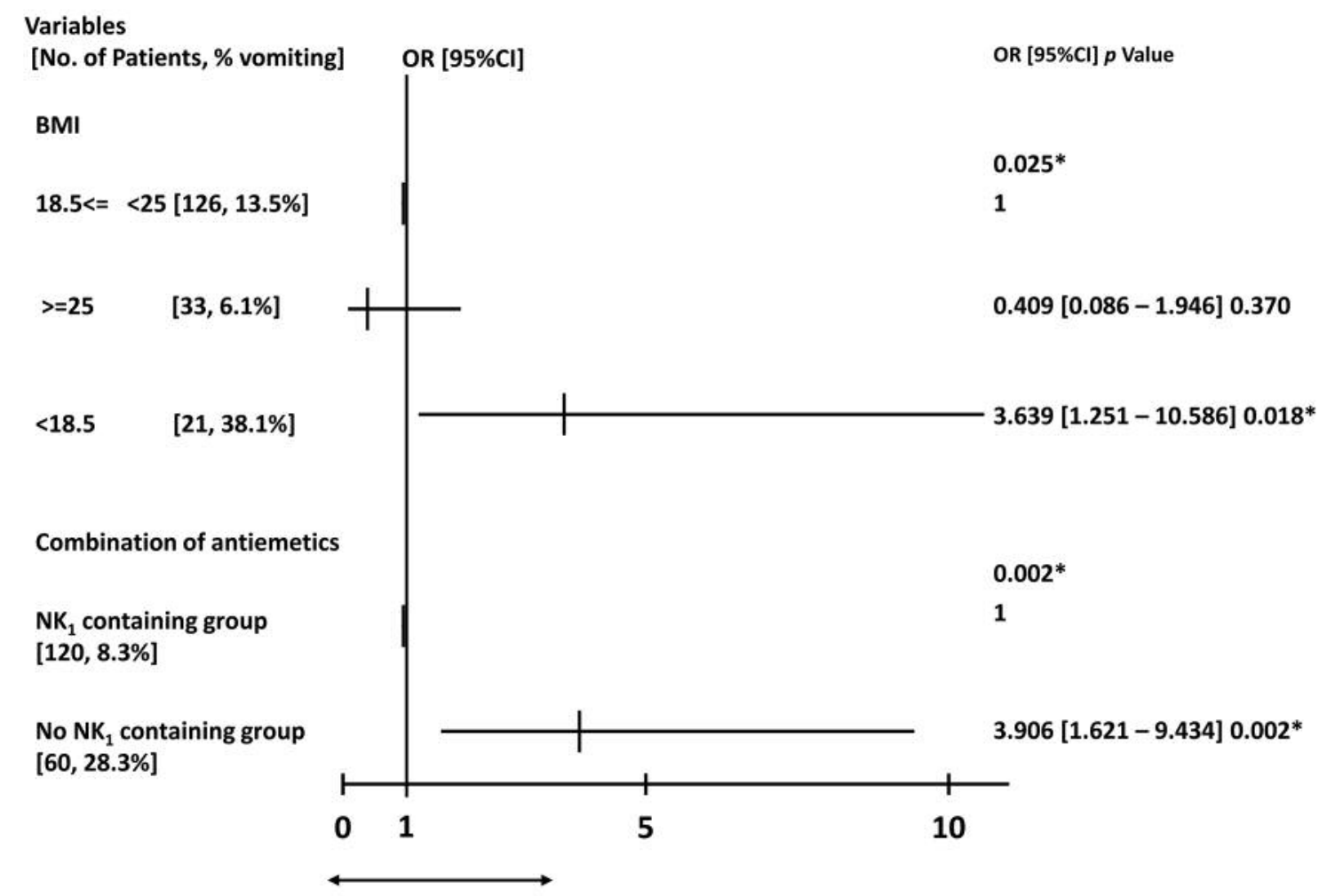

Figure 5. The results of multivariate regression analysis of vomiting. The variable of the combination of antiemetics was changed from four to two categories: the $N K_{l}$-containing group and the no-NK $K_{l}$-containing group. BMI and combination of antiemetics were significant variables, with p-Values of 0.025 and 0.002 , respectively. The OR for BMI less than 18.5 was 3.639 and p-Value was 0.018 . The OR for the no-NK -containing $^{-}$ group of antiemetic combinations was 3.906 and p-Value was 0.002. Asterisk points to statistical significance.

\section{References}

1 Rossi A, Bonadonna G, Valagussa P and Veronesi U: Multimodal treatment in operable breast cancer: Five-year results of the $\mathrm{cmf}$ programme. Br Med J (Clin Res Ed) 282(6274): 1427-1431, 1981. PMID: 6784849. DOI:10.1136/bmj.282.6274.1427

2 Andersson M, Madsen EL, Overgaard M, Rose C, Dombernowsky $\mathrm{P}$ and Mouridsen HT: Doxorubicin versus methotrexate both combined with cyclophosphamide, 5-fluorouracil and tamoxifen in postmenopausal patients with advanced breast cancer - a randomised study with more than 10 years follow-up from the danish breast cancer cooperative group. Danish breast cancer cooperative group (dbcg). Eur J Cancer 35(1): 39-46, 1999. PMID: 10211086.

3 French Adjuvant Study Group. Benefit of a high-dose epirubicin regimen in adjuvant chemotherapy for node-positive breast cancer patients with poor prognostic factors: 5-year follow-up results of French Adjuvant Study Group 05 randomized trial. J Clin Oncol 19(3): 602-611, 2001. PMID: 11157009. DOI: 10.1200/JCO.2001.19.3.602

4 Henderson IC, Berry DA, Demetri GD, Cirrincione CT, Goldstein LJ, Martino S, Ingle JN, Cooper MR, Hayes DF, Tkaczuk KH, Fleming G, Holland JF, Duggan DB, Carpenter JT, Frei E 3rd, Schilsky RL, Wood WC, Muss HB and Norton L: Improved outcomes from adding sequential Paclitaxel but not from escalating
Doxorubicin dose in an adjuvant chemotherapy regimen for patients with node-positive primary breast cancer. J Clin Oncol 21(6): 976983, 2003. PMID: 1263746.0 DOI: 10.1200/JCO.2003.02.063

5 Citron ML, Berry DA, Cirrincione C, Hudis C, Winer EP, Gradishar WJ, Davidson NE, Martino S, Livingston R, Ingle JN, Perez EA, Carpenter J, Hurd D, Holland JF, Smith BL, Sartor CI, Leung EH, Abrams J, Schilsky RL, Muss HB and Norton L: Randomized trial of dose-dense versus conventionally scheduled and sequential versus concurrent combination chemotherapy as postoperative adjuvant treatment of node-positive primary breast cancer: first report of Intergroup Trial C9741/Cancer and Leukemia Group B Trial J Clin Oncol 21(8): 1431-1439, 2003. PMID: 12668651. DOI: 10.1200/JCO.2003.09.081

6 Martin M, Pienkowski T, Mackey J, Pawlicki M, Guastalla JP, Weaver C, Tomiak E, Al-Tweigeri T, Chap L, Juhos E, Guevin R, Howell A, Fornander T, Hainsworth J, Coleman R, Vinholes J, Modiano M, Pinter T, Tang SC, Colwell B, Prady C, Provencher L, Walde D, Rodriguez-Lescure A, Hugh J, Loret C, Rupin M, Blitz S, Jacobs P, Murawsky M, Riva A, Vogel C; and Breast Cancer International Research Group 001 Investigators: Adjuvant docetaxel for node-positive breast cancer. N Engl J Med 352(22): 2302-2313, 2005. PMID: 15930421. DOI: 10.1056/NEJMoa043681

7 Roché H, Fumoleau P, Spielmann M, Canon JL, Delozier T, Serin D, Symann M, Kerbrat P, Soulié P, Eichler F, Viens P, Monnier A, Vindevoghel A, Campone M, Goudier MJ, Bonneterre J, Ferrero JM, 
Martin AL, Genève J, Asselain B: Sequential adjuvant epirubicinbased and docetaxel chemotherapy for node-positive breast cancer patients: the FNCLCC PACS 01 Trial. J Clin Oncol 24(36): 56645671, 2006. PMID: 17116941. DOI:10.1200/JCO.2006.07.3916

8 Ding W, Li Z, Wang C, Dai J, Ruan G and Tu C: Anthracycline versus nonanthracycline adjuvant therapy for early breast cancer: A systematic review and meta-analysis. Medicine (Baltimore) 97(42): e12908, 2018. PMID: 30335021. DOI: 10.1097/MD. 0000000000012908

9 Hasegawa Y, Tanino H, Horiguchi J, Miura D, Ishikawa T, Hayashi M, Takao S, Kim SJ, Yamagami K, Miyashita M, Konishi M, Shigeoka Y, Suzuki M, Taguchi T, Kubota T, Akazawa $\mathrm{K}$ and Kohno N: Randomized controlled trial of zoledronic acid plus chemotherapy versus chemotherapy alone as neoadjuvant treatment of her2-negative primary breast cancer (jonie study). PLoS One 10(12): e0143643, 2015. PMID: 26633806. DOI: 10.1371/journal.pone.0143643

10 Ishikawa T, Akazawa K, Hasegawa Y, Tanino H, Horiguchi J, Miura D, Hayashi M and Kohno N: Survival outcomes of neoadjuvant chemotherapy with zoledronic acid for her2negative breast cancer. J Surg Res 220: 46-51, 2017. PMID: 29180210. DOI: 10.1016/j.jss.2017.05.066

11 Trotti A, Colevas AD, Setser A, Rusch V, Jaques D, Budach V, Langer C, Murphy B, Cumberlin R, Coleman CN and Rubin P: CTCAE v3 0: development of a comprehensive grading system for the adverse effects of cancer treatment. Semin Radiat Oncol 13: 176-181, 2003. PMID: 12903007. DOI: 10.1016/s10534296(03)00031-6

12 International Council For Harmonisation of Technical Requirements for Pharmaceuticals for Human Use (ICH), https://www.ich.org/fileadmin/Public_Web_Site/ICH_Products/G uidelines/Efficacy/E6/E6_R2_Step_4_2016_1109.pdf (accessed 30 June 2019)

13 Robert V Carlson, Kenneth M Boyd, David J Webb: The revision of the Declaration of Helsinki: past, present and future Br J Clin Pharmacol 57(6): 695-713, 2004. PMID: 15151515. DOI: $10.1111 / \mathrm{j} .1365-2125.2004 .02103 . x$

14 Sekine I, Segawa Y, Kubota K and Saeki T: Risk factors of chemotherapy-induced nausea and vomiting: Index for personalized antiemetic prophylaxis. Cancer Sci 104(6): 711717, 2013. PMID: 23480814. DOI: $10.1111 /$ cas.12146

15 Warr D: Prognostic factors for chemotherapy induced nausea and vomiting. Eur J Pharmacol 722: 192-196, 2014. PMID: 24157977. DOI: 10.1016/j.ejphar.2013.10.015

16 Hesketh PJ, Aapro M, Street JC and Carides AD: Evaluation of risk factors predictive of nausea and vomiting with current standard-of-care antiemetic treatment: Analysis of two phase iii trials of aprepitant in patients receiving cisplatin-based chemotherapy. Support Care Cancer 18(9): 1171-1177, 2010. PMID: 19756774. DOI: 10.1007/s00520-009-0737-9

17 Lorusso V: Management of chemotherapy-induced nausea and vomiting by risk profile: Role of netupitant/palonosetron. Ther Clin Risk Manag 12: 917-925, 2016. PMID: 27354807. DOI: 10.2147/TCRM.S89215

18 Davidson W, Teleni L, Muller J, Ferguson M, McCarthy AL, Vick $\mathrm{J}$ and Isenring $\mathrm{E}$ : Malnutrition and chemotherapy-induced nausea and vomiting: Implications for practice. Oncol Nurs Forum 39(4): E340-345, 2012. PMID: 22750904. DOI: 10.1188/ 12.ONF.E340-E345
19 Australian Institute of Health and Welfare, Australian's Health 2018, https://www.aihw.gov.au/reports/australias-health/australiashealth-2018/contents/bmi-where-do-you-fit (accessed 30 May 2019)

20 Basch E, Prestrud AA, Hesketh PJ, Kris MG, Feyer PC, Somerfield MR, Chesney M, Clark-Snow RA, Flaherty AM, Freundlich B, Morrow G, Rao KV, Schwartz RN and Lyman GH: Antiemetics: American society of clinical oncology clinical practice guideline update. J Clin Oncol 29(31): 4189-4198, 2011. PMID: 21947834. DOI: 10.1200/JCO.2010.34.4614

21 Basch E, Prestrud AA, Hesketh PJ, Kris MG, Somerfield MR and Lyman GH: Antiemetic use in oncology: Updated guideline recommendations from ASCO. Am Soc Clin Oncol Educ Book 532-540, 2012. PMID:24451791. DOI: 10.14694/EdBook_AM. 2012.32 .532

222006 update of the ASCO recommendations for antiemetics in oncology: Guideline summary. J Oncol Pract 2(4): 193-195, 2006. PMID: 29452007. DOI: 10.1200/JOP.2006.2.4.193

23 Hesketh PJ, Bohlke K, Lyman GH, Basch E, Chesney M, ClarkSnow RA, Danso MA, Jordan K, Somerfield MR and Kris MG: Antiemetics: American society of clinical oncology focused guideline update. J Clin Oncol 34(4): 381-386, 2016. PMID: 26527784. DOI: $10.1200 / J C O .2015 .64 .3635$

24 Hesketh PJ, Kris MG, Basch E, Bohlke K, Barbour SY, Clark-Snow RA, Danso MA, Dennis K, Dupuis LL, Dusetzina SB, Eng C, Feyer PC, Jordan K, Noonan K, Sparacio D, Somerfield MR and Lyman GH: Antiemetics: American society of clinical oncology clinical practice guideline update. J Clin Oncol 35(28): 3240-3261, 2017. PMID: 28759346. DOI: 10.1200/JCO. 2017.74.4789

25 Berger MJ, Ettinger DS, Aston J, Barbour S, Bergsbaken J, Bierman PJ, Brandt D, Dolan DE, Ellis G, Kim EJ, Kirkegaard S, Kloth DD, Lagman R, Lim D, Loprinzi C, Ma CX, Maurer V, Michaud LB, Nabell LM, Noonan K, Roeland E, Rugo HS, Schwartzberg LS, Scullion B, Timoney J, Todaro B, Urba SG, Shead DA and Hughes M: Nccn guidelines insights: Antiemesis, version 2.2017. J Natl Compr Canc Netw 15(7): 883-893, 2017. PMID: 28687576. DOI: 10.6004/jnccn.2017.0117

26 Einhorn LH, Rapoport B, Navari RM, Herrstedt J and Brames MJ: 2016 updated mascc/esmo consensus recommendations: Prevention of nausea and vomiting following multiple-day chemotherapy, high-dose chemotherapy, and breakthrough nausea and vomiting. Support Care Cancer 25(1): 303-308, 2017. PMID: 27815710. DOI: 10.1007/s00520-016-3449-y

27 Razvi Y, Chan S, McFarlane T, McKenzie E, Zaki P, DeAngelis C, Pidduck W, Bushehri A, Chow E and Jerzak KJ: Asco, ncen, mascc/esmo: A comparison of antiemetic guidelines for the treatment of chemotherapy-induced nausea and vomiting in adult patients. Support Care Cancer 27(1): 87-95, 2019. PMID: 30284039. DOI: 10.1007/s00520-018-4464-y 